\section{Honorary authorship in Geriatric Literature: do authors adhere to the ICMJE-guidelines?}

\author{
Alex Verhemel, ${ }^{1,2}$ Yalda Dahi, ${ }^{1}$ \\ Selay Kakar, ${ }^{1}$ Pravesh S. Gadjradj ${ }^{1}$ \\ ${ }^{1}$ Department of Neurosurgery, Leiden \\ University Medical Center, University \\ Neurosurgical Center Holland (UNCH), \\ Leiden; ${ }^{2}$ Department of Geriatrics, \\ Elisabeth-TweeSteden Hospital, Tilburg, \\ The Netherlands
}

\section{Abstract}

To protect appropriate authorship, the International Committee of Medical Journal Editors (ICMJE) formulated a guideline on authorship. Researchers not fulfilling these criteria and still enlisted as author are seen as honorary authors (HA).

The objective of this study is to assess authorship decision making and the proportion of HA in journals in the field of geriatrics and gerontology.

Corresponding authors of six highimpact journals in geriatrics and gerontology were sent a survey. The survey consisted of three parts: i) demographics of the respondent; ii) awareness of authorship guidelines; and iii) authorship decisions made for the paper they are authors of. Respondents were also asked if one of their coauthors does not deserve authorship. This is defined as self-perceived HA. Furthermore, respondents were asked if any of their co-authors only performed tasks from a list of non-authorship tasks. This is defined as ICMJE-defined HA.

Of the 1592 contacted authors, 528 filled in a survey (response rate $33.2 \%$ ). $84.4 \%$ was aware of the ICMJE-guidelines, but $44.2 \%$ was unaware of the issue of HA. The proportion of self-perceived HA was $12.7 \%$. Independent factors associated with more self-perceived HA were having a senior member automatically enlisted as coauthor [odds ratio (OR) 3.4, 95\% confidence interval (CI) 1.8 to 6.4 ] and have gotten the suggestion to include an HA (OR 11.1, 95\% CI 4.4 to 27.9). The proportion of ICMJEdefined HA was $39.3 \%$. The journal surveyed (OR 1.2, 1.0 to 1.3) was associated with more, and awareness of the ICMJE (OR 0.5, 95\% CI 0.3 to 0.9 ) was associated with less ICMJE-defined HA respectively. Having a senior member automatically enlisted as co-author (OR 2.1 95\% CI 1.3 to 3.4 ) and having anyone suggest to include an HA (OR $4.895 \%$ CI 1.8 to 12.8 ) were also associated with more ICMJE-defined HA.

More than one out of ten of the corresponding authors thinks that based on the ICMJE-guidelines, one or more of their coauthors did not deserve authorship. A stricter journal policy and more awareness of the ICMJE-guidelines could help reduce the proportion of HA.

\section{Introduction}

Significant contributions made by an individual to a published paper merits authorship. As most research is done in teams, multiple authors might qualify for authorship, sharing the responsibility and accountability of the produced manuscript. To attain a certain degree of objectivity in meriting authorship and to protect appropriate authorship, the International Committee of Medical Journal Editors (ICMJE) formulated a guideline on authorship. ${ }^{1}$ This guideline contains 4 criteria which should be met to qualify as co-author: i) Substantial contributions to the conception or design of the work; or the acquisition, analysis, or interpretation of data for the work; ii) Drafting the work or revising it critically for important intellectual content; iii) Final approval of the version to be published; and iv) Agreement to be accountable for all aspects of the work in ensuring that questions related to the accuracy or integrity of any part of the work are appropriately investigated and resolved.

Researchers not fulfilling all these criteria and still enlisted as author are regarded as honorary authors (also known as courtesy authors or gift authors). Honorary authorship (HA) can be seen as unethical or harmful to researchers and the whole scientific community. ${ }^{2,3}$ Through HA researchers can raise the quota of published papers, possibly denying colleagues of well-earned research funding or promotion to a higher title in the academic field. Furthermore, having a senior member of staff as an HA might influence the critical appraisal by colleagues in the peer-review system.

Previous studies have attempted to estimate the proportion of HA in different disciplines such as radiology, dermatology and general surgery. ${ }^{4-9}$

An evaluation of Geriatric literature has not been made. As estimating the proportion of the problem may help raise awareness on the issue, the goal of this study is to assess the proportion of HA in gerontological journals.
Correspondence: Pravesh S. Gadjradj, Department of Neurosurgery, Leiden University Medical Center, Albinusdreef 2, 2333 ZA Leiden, The Netherlands. Tel.: +316.34286813.

E-mail: p.gadjradj@erasmusmc.nl

Key words: Honorary authorship; survey; geriatrics.

Acknowledgments: the authors would like to thank all respondents for sharing their opinions us.

Contributions: the study was designed by $\mathrm{AV}$, YD and PG. AV, YD and SK collected the data. AV and PG performed the data analysis and interpreted the data. AV and PG drafted the first version of the manuscript. YD and SK revised the manuscript. PG supervised the manuscript. All authors reviewed the manuscript and approved the final version for submission.

Conflict of interest: the authors declare no potential conflict of interest.

Ethics approval: as no patients were involved for this research, the Institutional Review Board waived the need for formal approval.

Availability of data and materials: upon request.

Received for publication: 4 July 2020.

Revision received: 28 August 2020.

Accepted for publication: 4 September 2020.

This work is licensed under a Creative Commons Attribution-NonCommercial 4.0 International License (CC BY-NC 4.0).

${ }^{\circ}$ Copyright: the Author(s), 2020

Licensee PAGEPress, Italy

Geriatric Care 2020; 6:9227

doi:10.4081/gc.2020.9227

\section{Materials and Methods}

Based on the literature a 19-question survey was formulated..$^{7-10}$ The survey consisted of three parts: i) demographics of the respondent; ii) awareness of authorship guidelines; and iii) authorship decisions made for the paper they are authors of. At the end of the survey, respondents were asked if they think one of their coauthors on the surveyed paper does not deserve authorship. This is defined as self-perceived HA. Furthermore, respondents were asked if any of their co-authors only performed tasks from a list and nothing more than tasks of this list. The list contains tasks such as contributing illustrations, recruiting study subject and obtain funding, amongst others. This is defined as ICMJE-defined HA. 
Six journals in the field of geriatrics in 2017 were selected. These journals were the Journal of the American Geriatrics Society (J Am Geriatr Soc), Neurobiology of Aging, Journal of the American Medical Directors Association (J Am Med Dir Assoc), Alzheimer's \& Dementia, BMC Geriatrics and The Journals of Gerontology: Series A (J Gerontol A). Manuscripts were eligible if they were original research or review articles and had more than one author. E-mail addresses of the corresponding authors of the included articles were collected and used to send the survey using SurveyMonkey (Palo Alto, CA). Authors were mailed in early 2018, with reminders sent to increase the response rate.

\section{Statistical analysis}

Data were analyzed using the Statistical Package for Social Sciences, version 21.0 for Windows (SPSS, Inc.). Descriptive statistics were used to present data into valid percentages. Association between categorical variables was tested using chi-squared test. To identify factors associated with both ICMJE-defined and self-perceived, a multilevel logistic regression analyses were performed. Odds ratios (ORs) are presented with their 95\% confi- dence intervals (CI). Statistical significance was set at $\mathrm{P}<0.05$.

\section{Results}

The survey was eventually sent to 1592 functional email addresses of which 528 answers were included for analysis (response rate 33.2\%). Figure 1 gives an overview of the study procedures and the response rates per surveyed journal. Response rates per journal varied from $22.4 \%$ (Alzheimer's \& Dementia) to $35.7 \%$ (J Gerontol A). Characteristics of respondents are shown in Table 1. Most of the respondents surveyed were $\mathrm{PhD} /$ researchers $(57.7 \%)$, followed by gerontologists (16.4\%) and other medical doctors (14.8\%). Overall, respondents tend to be more experienced in their academic career: $61.2 \%$ had authored more than 26 peer-reviewed articles; $49.5 \%$ had more than 10 years of professional experience and $64.3 \%$ held the title of (associate/assistant) professor. Geographically, most respondents hailed from Europe $(41.9 \%)$ and North America $(39.4 \%)$

Table 2 gives an overview of the answers regarding awareness of the ICMJE-guidelines and the steps taken to determine authorship by the respondents. Before the distribution of the survey, $84.4 \%$ were aware of the ICMJE-guidelines on authorship. Of the respondents that were unaware of the guidelines, $16.1 \%$ followed no guidelines on authorship while $69.4 \%$ had institutional guidelines which were followed. Of all respondents, $44.2 \%$ were unaware of the issue of HA. Furthermore, $5.9 \%$ of the respondents received suggestions to include an honorary author; $14.8 \%$ of the respondents were employed at departments, where the senior member is automatically enlisted as coauthor on all submitted manuscripts. This was never or rarely justified by $65.4 \%$ of the before mentioned respondents.

Of the papers surveyed, the order of authors was mostly decided by the authors as a group $(44.2 \%)$ or by the first author $(32.7 \%)$. In two articles the funding source of the study decided the order. The order of authorship was decided by the amount of contribution to the paper (35.8\%). Except for the determination of the position of the last author who provided the concept, supervision and took responsibility for all working steps $(53.6 \%)$.

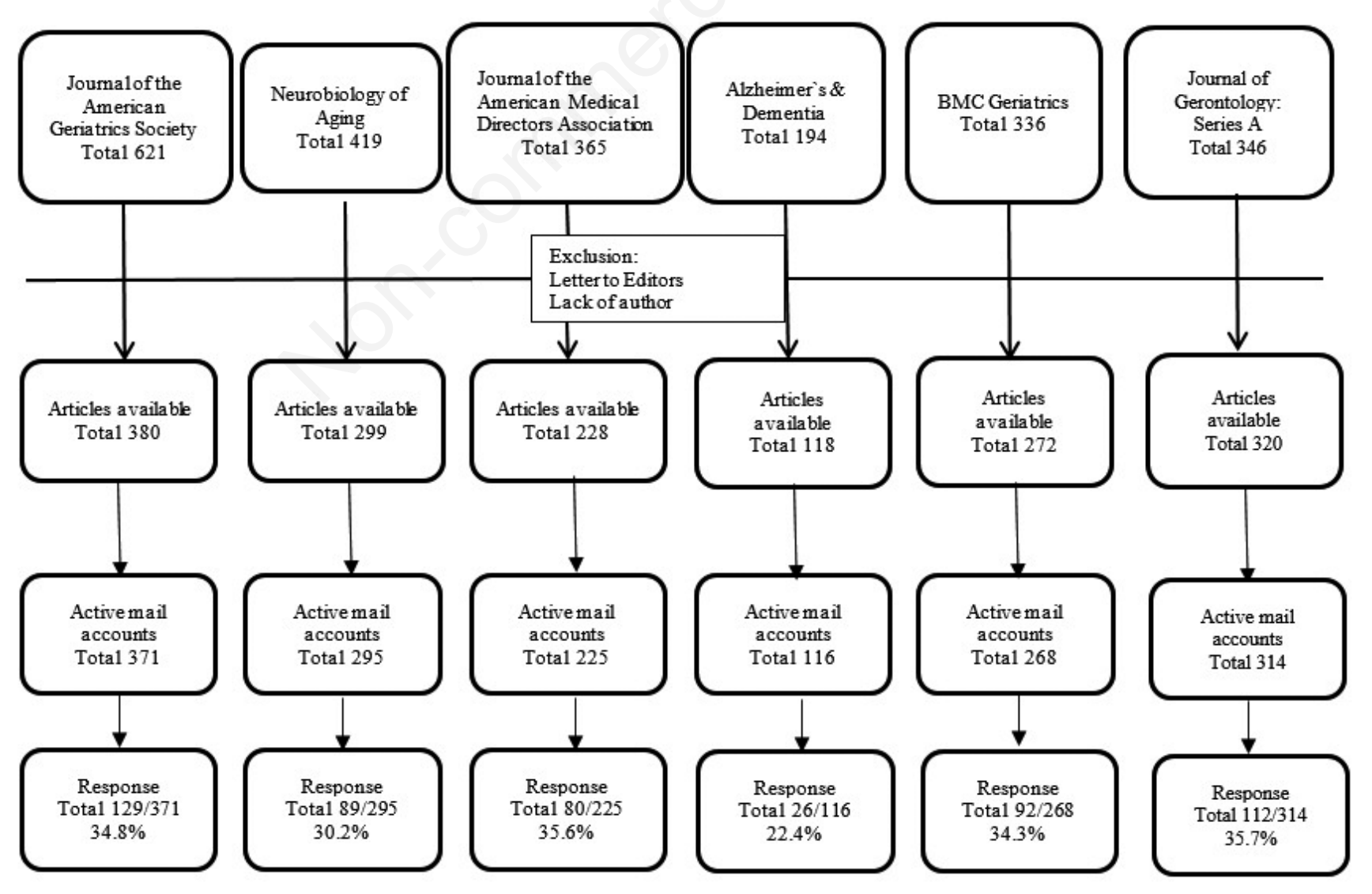

Figure 1. Flowchart of the study procedures. 
When asking respondents if coauthors only performed tasks which alone should not lead to authorship, $39.3 \%$ of respondents answered yes (ICMJE-defined HA). Most performed non-authorship tasks included reviewing the manuscript $(28.2 \%)$ and approving the manuscript before submission (22.5\%). Univariate analysis revealed that articles published in the ( $\mathrm{J}$ Am Geriatr Soc, $\mathrm{P}=0.004$ ), were associated with less ICMJE-defined HA. Having a senior member automatically included on all manuscripts and receiving suggestions to include an honorary author were both significantly $(\mathrm{P}<0.001)$ associated with more ICMJE-defined HA.

The proportion of self-perceived HA was $12.7 \%$ overall. On univariate analysis, having a senior member automatically enlisted as author and having anyone suggest to include an honorary author were both associated $(\mathrm{P}<0.001)$ with more selfperceived HA.

Gender of the respondent, continent of employment and tenure were not significantly associated with ICMJE-defined of self-perceived HA. Awareness of the ICMJE-guidelines was a trend for both types of $\mathrm{HA}(0.05<\mathrm{P}<0.10)$.

Multiple variable logistic regression analysis was performed to identify variables independently associated with both forms of HA. Having a senior member automatically enlisted as co-author on all manuscripts (OR 3.4, 95\%CI 1.8 to 6.4 ) and having anyone suggest to include an HA (OR $11.1,95 \% \mathrm{CI} 4.4$ to 27.9 ) were both significantly associated with more self-perceived HA. The journal surveyed and awareness of the ICMJE-guidelines were both not associated with self-perceived HA.

However, the journal surveyed (OR $1.2,95 \% \mathrm{CI} 1.0$ to 1.3 ) and awareness of the ICMJE-guidelines (OR $0.5,95 \%$ CI 0.3 to 0.9 ) were significantly associated with more or less ICMJE-defined HA respectively. Having a senior member automatically enlisted as co-author (OR $2.1,95 \% \mathrm{CI}$ 1.3 to 3.4 ) and having anyone suggest to include an HA (OR 4.8, 95\%CI 1.8 to 12.8) were also associated with more ICMJE-defined HA.

\section{Discussion}

The present study gives an overview of the decision-making regarding authorship positions of 528 corresponding authors of manuscripts published in six renowned journals in the field of Gerontology. Of the respondents, $84.4 \%$ was aware of the ICMJE-guidelines, but $44.2 \%$ was unaware of the issue of HA. The proportion of selfperceived HA was $12.7 \%$. Independent factors associated with more self-perceived HA were having a senior member automatically enlisted as co-author and being advised to include an HA. The proportion of ICMJE-defined HA was 39.3\%. The journal surveyed and awareness of the IMCJEguidelines were associated with less ICMJE-defined HA, while having a senior member automatically enlisted and receiving suggestion to include an HA were also associated with more ICMJE-defined HA.

Even though all of the surveyed journals state to adhere to authorship guidelines,

Table 1. Characteristics of the respondents.

\begin{tabular}{|c|c|}
\hline & $\mathrm{N}(\%)$ \\
\hline Primary profession & 452 \\
\hline Geriatrician/ Gerontologist & $74(16.4 \%)$ \\
\hline Other MD & $67(14.8 \%)$ \\
\hline $\mathrm{PhD} /$ Researcher & $261(57.7 \%)$ \\
\hline Statistician & $6(1.3 \%)$ \\
\hline Other & $44(9.7 \%)$ \\
\hline Gender & 450 \\
\hline Male & $222(49.3 \%)$ \\
\hline Female & $228(50.7 \%)$ \\
\hline $\begin{array}{l}\text { Peer-reviewed articles } \\
\text { authored }\end{array}$ & 528 \\
\hline$<5$ & $76(14.4 \%)$ \\
\hline $6-10$ & $43(8.1 \%)$ \\
\hline $11-15$ & $35(6.6 \%)$ \\
\hline $16-20$ & $28(5.3 \%)$ \\
\hline $21-25$ & $23(4.4 \%)$ \\
\hline$>26$ & $323(61.2 \%)$ \\
\hline Academic title held & 428 \\
\hline Professor & $115(26.9 \%)$ \\
\hline Associate professor & $83(19.4 \%)$ \\
\hline Assistant professor & 77 (18.0\%) \\
\hline Instructor/ Lecturer & $27(6.3 \%)$ \\
\hline Fellow/ Resident & $49(11.4 \%)$ \\
\hline Other & $77(18.0 \%)$ \\
\hline $\begin{array}{l}\text { Length of professional } \\
\text { experience }\end{array}$ & 455 \\
\hline $1-2$ years & $53(11.6 \%)$ \\
\hline $3-5$ years & $78(17.1 \%)$ \\
\hline $6-10$ years & $99(21.8 \%)$ \\
\hline$>10$ years & $225(49.5 \%)$ \\
\hline Continent employed & 528 \\
\hline Europe & $221(41.9 \%)$ \\
\hline North America & $208(39.4 \%)$ \\
\hline Asia and Oceania & $84(15.9 \%)$ \\
\hline South America & $14(2.7 \%)$ \\
\hline Africa & $1(0.2 \%)$ \\
\hline
\end{tabular}

self-perceived (from 8.6 to $17.7 \%$ ) and ICMJE-defined (22.9 to $50.0 \%$ ) were prevalent in all journals. Logistic regression analyses showed that articles published in the J Am Geriatr Soc were associated with less ICMJE-defined HA. Even though we cannot clarify this directly, we suggest that including a comprehensive authors contributions statement at the end of all manuscripts may play a role.

Furthermore, the results of the current study clearly show a discrepancy between awareness and application of the ICMJEguidelines, as $84 \%$ is aware of the guidelines, but still $39.4 \%$ of the articles have an ICMJE-defined honorary author. Despite this inconsistency, awareness of these guidelines is associated with less HA according to the regression analyses. Risk factors for HA included automatic enlistment of a senior member on the manuscript and receiving suggestions to include an honorary author. This is in line with the literature regarding coercive authorship. This is a frequent described form of HA, which is an expression of the noxious hierarchal relationships of junior researchers with senior members of department chairs. ${ }^{3,11}$

A recent review on responsible authorship summarized means to prevent authorship misuse. ${ }^{3}$ The authors suggested that training in publication ethics of research groups by universities and thus increasing awareness might limit unjustified authorship. Another recommendation is unambiguous endorsement of authorship guidelines by medical journals. Lastly, the authors proposed the formation of local committees at academic departments to discuss and resolve authorship disputes. Other researchers advocate the revision of the ICMJE-guidelines as a method to limit honorary authorships. Furthermore, certain scholars counsel a shift from a system with citation-based evaluative metrics towards a system in which individual authorship contributions in percentages play a part in the citation metrics. ${ }^{11,12}$

A frequently discussed matter of crosssectional research is the response rate and its relationship to selection bias. ${ }^{13-15}$ A low response rate can lead to over- or underestimation of the proportion of HA. Even though some articles on survey methodology and journals specify rates of minimum response rates, these rates are arbitrary. Regarding this study, almost one out of three authors filled in a survey, which is comparable to recent studies. ${ }^{4-7,10}$ Another limitation might be the decision to mail the survey to the corresponding author, usually a senior member of staff, as junior researchers may often have temporary employments at research institutes. By sur- 
veying mostly senior authors, the frequent beneficiaries of HA, one could hypothesize the underestimation of reported HA in comparison to having surveyed only junior researchers. Despite these potential limitations, the results of this study irrefutable as all the journals surveyed, have a policy that HA in not acceptable.
This study shows high awareness of the ICMJE guidelines by the corresponding authors. However, more than one out of ten of the corresponding authors reported that based on the ICMJE-guidelines, the contributions made by one or more of the coauthors did not justify authorship. The proportion of IMCJE- defined HA was even almost three times higher than the proportion of self-perceived HA, suggesting a knowledge gap on the guidelines. A more uniform and stricter journal policy regarding authorship and more awareness of the ICMJEguidelines by authors could help reduce the proportion of HA.

Table 2. Awareness of authorship guidelines and the determination of authorships.

\begin{tabular}{|c|c|c|c|}
\hline & $\mathbf{N}(\%)$ & & $\mathbf{N}(\%)$ \\
\hline $\begin{array}{l}\text { Before taking the survey, were you aware } \\
\text { of the ICMJE-guidelines on authorship? }\end{array}$ & 455 & $\begin{array}{l}\text { Did anyone suggest to include an honorary author? } \\
\text { Yes }\end{array}$ & $\begin{array}{l}444 \\
26(5.9 \%)\end{array}$ \\
\hline Yes & $384(84.4 \%)$ & No & $418(94.1 \%)$ \\
\hline No & $71(15.6 \%)$ & What was your primary role in the article? & 455 \\
\hline \multirow{2}{*}{$\begin{array}{l}\text { If unaware, were you aware of other authorship } \\
\text { guidelines? }\end{array}$} & \multirow[t]{2}{*}{124} & Wrote all or most of the article & $341(74.9 \%)$ \\
\hline & & Wrote minor parts of the article & $5(1.1 \%)$ \\
\hline No guidelines are followed & $86(69.4 \%)$ & $\begin{array}{l}\text { Only revised the article and made corrections and changes } \\
\text { in content }\end{array}$ & $11(2.4 \%)$ \\
\hline Other & $18(14.5 \%)$ & & $37(8.1 \%)$ \\
\hline \multirow{2}{*}{$\begin{array}{l}\text { Before taking the survey, were you aware of the } \\
\text { issue of honorary authorship? }\end{array}$} & \multirow[t]{2}{*}{448} & Performed majority of data collection/ analysis & $13(2.9 \%)$ \\
\hline & & & $48(10.5 \%)$ \\
\hline ( & $\begin{array}{l}250(55.8 \%) \\
198(44.2 \%)\end{array}$ & $\begin{array}{l}\text { Did any of your coauthors performed only one or } \\
\text { more tasks non-authorship tasks and nothing else }\end{array}$ & \\
\hline $\begin{array}{l}\text { Is there a senior member of your department, } \\
\text { including section chief or department head, who is } \\
\text { automatically listed as authors on all submitted } \\
\text { manuscripts? }\end{array}$ & 453 & $\begin{array}{l}\text { related to study design, manuscript preparation etc.? } \\
\text { J Am Geriatr Soc } \\
\text { Neurobiol Aging }\end{array}$ & $\begin{array}{l}455 \\
24(22.9 \%) \\
33(41.8 \%) \\
\end{array}$ \\
\hline Yes & $67(14.8 \%)$ & J Am Med Dir Assoc & $37(49.3 \%)$ \\
\hline No & $358(79.0 \%)$ & Alzheimers Dement & $12(50.0 \%)$ \\
\hline Don't know & $28(6.2 \%)$ & BMC Geriatr & $35(41.7 \%)$ \\
\hline If so, do you feel this is justified? & 246 & J Gerontol A & $38(43.2 \%)$ \\
\hline Never justified & $98(39.8 \%)$ & Which tasks were performed? & \\
\hline Rarely justified & $63(25.6 \%)$ & Supervising/recruiting coauthors & $49(9.3 \%)$ \\
\hline Sometimes justified & $44(17.9 \%)$ & Obtaining funding or material support & $77(14.6 \%)$ \\
\hline Most of the time justified & $22(8.9 \%)$ & Recruiting study subjects & $81(15.3 \%)$ \\
\hline Always justified & $19(7.7 \%)$ & Performing cases used in the study & $29(5.5 \%)$ \\
\hline Regarding your paper, who decided the order of & 455 & Contributing illustrations & $15(2.8 \%)$ \\
\hline authorship? & & Reviewing the manuscript & $152(28.8 \%)$ \\
\hline First author & $149(32.7 \%)$ & Approving the manuscript before submission to a journal & $119(22.5 \%)$ \\
\hline Senior author & $85(18.7 \%)$ & Signing statement of copyright transfer to journal & $53(10.0 \%)$ \\
\hline Authors decided as a group & $201(44.2 \%)$ & According to your current understanding, do you & 455 \\
\hline The funding source of this study & $2(0.2 \%)$ & $\begin{array}{l}\text { Delleve that any of your coauthors enlisted for the } \\
\text { current article did not make sufficient contributions }\end{array}$ & \\
\hline Other & $18(4.0 \%)$ & to merit co-authorship? & \\
\hline What criteria did you use to decide the order of & 450 & J Am Geriatr Soc & $9(8.6 \%)$ \\
\hline $\begin{array}{l}\text { authorsnip? The authors are listed: } \\
\text { In the order of the amount each contributed }\end{array}$ & $161(35.8 \%)$ & Neurobiol Aging & $14(17.7 \%)$ \\
\hline In the order of the amount each contributed, except the last & $9(2.0 \%)$ & J Am Med Dir Assoc & $12(16.0 \%)$ \\
\hline $\begin{array}{l}\text { author, who is the most senior in the group but did not } \\
\text { contribute to the study }\end{array}$ & & BMC Geriatr & $9(10.1 \%)$ \\
\hline $\begin{array}{l}\text { In the order of the amount each contributed, except the last } \\
\text { author, who provided the concept, supervision and } \\
\text { responsibility for all steps }\end{array}$ & $241(53.6 \%)$ & J Gerontol A & $10(11.4 \%)$ \\
\hline In alphabetical order & $2(0.4 \%)$ & & \\
\hline Other & $37(8.2 \%)$ & & \\
\hline
\end{tabular}


ture. World J Surg 2019;43:696-703.

6. Eisenberg RL, Ngo L, Boiselle PM, Bankier AA. Honorary authorship in radiologic research articles: assessment of frequency and associated factors. Radiology 2011;259:479-86.

7. Flanagin A, Carey LA, Fontanarosa PB, et al. Prevalence of articles with honorary authors and ghost authors in peerreviewed medical journals. JAMA 1998;280:222-4.

8. Mowatt G, Shirran L, Grimshaw JM, et al. Prevalence of honorary and ghost authorship in Cochrane reviews. JAMA 2002;287:2769-71.

9. Wislar JS, Flanagin A, Fontanarosa PB, Deangelis CD. Honorary and ghost authorship in high impact biomedical journals: a cross sectional survey. BMJ 2011;343:d6128.

10. Gadjradj PS, Fezzazi RE, Meppelder CA, et al. Letter: Honorary Authorship in Neurosurgical Literature: A Cross-sec- tional Analysis. Neurosurgery 2018;82: E25-E8.

11. Kovacs J. Honorary authorship epidemic in scholarly publications? How the current use of citation-based evaluative metrics make (pseudo)honorary authors from honest contributors of every multi-author article. J Med Ethics 2013;39: 509-12.

12. Kovacs J. Honorary authorship and symbolic violence. Med Health Care Philos 2017;20:51-9.

13. Chung KC. Survey response rate, a guide for readers and authors. J Hand Surg Am 2014;39:421-2.

14. Draugalis JR, Plaza CM. Best practices for survey research reports revisited: implications of target population, probability sampling, and response rate. Am J Pharm Educ 2009;73:142.

15. Parekh AD, Bates JE, Amdur RJ. Response rate and nonresponse bias in oncology survey studies. Am J Clin Oncol 2020;43:229-30. 